\section{Recovery of Gold(III) Ions by a Chitosan- coated Magnetic Nano-adsorbent}

\author{
Yang-Chuang Chang and \\ Dong-Hwang Chen* \\ Department of Chemical Engineering \\ National Cheng Kung University \\ Tainan, Taiwan 701, R.O.C. \\ Tel: 886-6-2757575 Ext.62680 \\ Fax: 886-6-2344496 \\ E-mail: chendh@mail.ncku.edu.tw \\ ${ }^{*}$ All correspondence should be addressed to \\ Dong-Hwang Chen
}

\begin{abstract}
The monodisperse chitosan-coated $\mathrm{Fe}_{3} \mathrm{O}_{4}$ nanoparticles with a mean diameter of $13.5 \mathrm{~nm}$ and $4.92 \mathrm{wt} \%$ chitosan were used as an anionic magnetic nano-adsorbent for the recovery of $\mathrm{Au}$ (III) ions from aqueous solutions. It was found that $\mathrm{Au}$ (III) ions could be fast and efficiently adsorbed, and the adsorption capacity increased with the decrease in $\mathrm{pH}$ due to the protonation of the amino groups of chitosan. The adsorption data obeyed the Langmuir equation with a maximum adsorption capacity of $59.52 \mathrm{mg} / \mathrm{g}(1210 \mathrm{mg} / \mathrm{g}$ based on the weight of chitosan) and a Langmuir adsorption equilibrium constant of $0.066 \mathrm{l} / \mathrm{mg}$. From the studies on the adsorption kinetics and thermodynamics of $\mathrm{Au}$ (III) ions, it was found that the adsorption process obeyed the pseudo-second-order kinetic model. Furthermore, the time required to reach the equilibrium was significantly shorter than those using the micro-sized adsorbents due to the large available surface area.
\end{abstract}

\section{Keywords}

gold(III); adsorption; chitosan; magnetic

\section{Introduction}

The recovery of precious metals such as silver, gold and platinum group metals is always attracting considerable attention due to the increasing industrial need and limiting sources. Besides the traditional precipitation method, solvent extraction and ion exchange techniques are usually used [15]. Although the former usually has relatively high efficiency and selectivity, the latter is sometime preferred because of the advantages that the mixing and settling requirements are usually more easily achieved as well as the utilization and loss of solvent can be eliminated.

The natural polysaccharide chitosan and its derivatives have great potential applications in the areas of biotechnology, biomedicine, food ingredients and cosmetics [6-11]. Owing to the abundant amino groups, chitosan and its derivatives also have good capability for the uptake of metal ions via the chelation or ion exchange mechanisms, depending on the kind of metal ions and the $\mathrm{pH}$ of solution [12-17]. Chitosan beads and chitosan-inorganic composites for the adsorption of metal ions were usually prepared by crosslinking the amino groups on chitosan with dialdehyde such as glutaraldehyde via a Schiff's reaction [18-21]. They were submicron to micron-sized and needed large internal porosities to ensure adequate surface area for adsorption. However, the diffusion limitation within the particles led to the decreases in the adsorption rate and available capacity.

Recently, we developed a novel magnetic nano-adsorbent with $\mathrm{Fe}_{3} \mathrm{O}_{4}$ nanoparticles as cores and chitosan as ionic exchange groups. It could be easily manipulated by an external magnetic field, and has been shown to be quite fast and efficient for the adsorption of $\mathrm{Cu}(\mathrm{II})$ ions and acid dyes due to high specific surface area and the absence of internal diffusion resistance [22-23]. Also, it could be used as a magnetic nano-carrier for targeted cancer therapy [24]. In this work, we further demonstrate the feasibility of the chitosan-coated magnetic nano-adsorbent in the recovery of metal anions using the valuable $A u(I I)$ ions as the model compound. The corresponding adsorption kinetics and thermodynamics were studied.

\section{Experimental}

Chitosan (low-viscous) and ferrous chloride tetrahydrate were purchased from Fluka (Buchs). Carbodiimide (cyanamide, $\mathrm{CH}_{2} \mathrm{~N}_{2}$ ) was supplied by Sigma Chemical Co. (St. Louis, MO). Ferric chlorides, 6-hydrate was purchased from J. T. Baker (Phillipsburg). Ammonium hydroxide (29.6\%) was supplied by TEDIA (Fairfield). Hydrogen tetrachloroaurate was supplied by Alfa (Ward Hill, MA). All other chemicals were the guaranteed or analytic grade reagents and used as received.

Chitosan-coated magnetic nano-adsorbent was prepared according to our previous work [22]. $\mathrm{Fe}_{3} \mathrm{O}_{4}$ nanoparticles were prepared by co-precipitation method and chitosan was carboxymethylated. For the binding of carboxymethyl chitosan, $100 \mathrm{mg}$ of $\mathrm{Fe}_{3} \mathrm{O}_{4}$ nanoparticles were first added to 2 
Table 1

Langmuir and Freundlish isotherm constants for the adsorption of Au(III) ions on the chitosan-coated magnetic nano-adsorbent

Langmuir

Freundlich

\begin{tabular}{l}
$\frac{q_{\mathrm{m}}(\mathrm{mg} / \mathrm{g})}{59.52} \frac{K_{\mathrm{L}} \times 100(\mathrm{l} / \mathrm{mg})}{6.589}-\frac{R^{2}}{1.000}$ \\
\hline
\end{tabular}

$\mathrm{ml}$ of buffer $\mathrm{A}(0.003 \mathrm{M}$ phosphate, $\mathrm{pH} 6,0.1 \mathrm{M} \mathrm{NaCl})$. Then, the reaction mixture was sonicated for 10 min after adding $0.5 \mathrm{ml}$ of carbodiimide solution $(0.025 \mathrm{~g} / \mathrm{ml}$ in buffer A). Finally, $2.5 \mathrm{ml}$ of carboxymethyl chitosan solution $(50 \mathrm{mg} / \mathrm{ml}$ in buffer A) was added and the reaction mixture was sonicated for $60 \mathrm{~min}$. The product was recovered from the reaction mixture by a permanent magnet, and then washed with water and ethanol. The resultant chitosan-coated magnetic nano-adsorbent was monodisperse, with a mean diameter of $13.5 \mathrm{~nm}, 4.92 \mathrm{wt} \%$ chitosan, and an isoelectric point of 5.95. The characterization methods and other properties could be obtained in our previous works [22-24].

The adsorption of $\mathrm{Au}(\mathrm{III})$ ions by the chitosan-coated magnetic nano-adsorbent was investigated in aqueous solutions at $\mathrm{pH}$ 2-10. In general, $105.17 \mathrm{mg}$ magnetic nanoadsorbent (i.e., $5.17 \mathrm{mg}$ chitosan on $100 \mathrm{mg} \mathrm{Fe}_{3} \mathrm{O}_{4}$ ) was added to $5 \mathrm{ml}$ of hydrogen tetrachloroaurate solution. The adsorption isotherms were investigated at $25^{\circ} \mathrm{C}$, a contact time of $12 \mathrm{~h}$, and various $\mathrm{Au}(\mathrm{III})$ ion concentrations (200-3000 $\mathrm{mg} / \mathrm{l})$. The magnetic nano-adsorbent was removed magnetically from the solution and the concentrations of $\mathrm{Au}$ (III) ions were determined using a GBC Avanta atomic absorption spectrometer. The adsorption kinetics was studied at $\mathrm{pH} 2,15-35^{\circ} \mathrm{C}$, and various $\mathrm{Au}(\mathrm{III})$ ion concentrations (644$1539 \mathrm{mg} / \mathrm{l})$. At various time intervals, the magnetic nanoadsorbent was removed magnetically and the concentrations of $\mathrm{Au}(\mathrm{III})$ ions in solutions were determined.

\section{Results and discussion}

\section{Effect of pH on adsorption capacity}

The effect of $\mathrm{pH}$ on the adsorption of $\mathrm{Au}(\mathrm{III})$ ions by the chitosan-coated magnetic nano-adsorbent at $25^{\circ} \mathrm{C}$ and an initial Au(III) ion concentration of $1039 \mathrm{mg} / \mathrm{l}$ was illustrated in Fig. 1. It was found that the adsorption capacity of $A u(I I)$ ions increased with the decrease in $\mathrm{pH}$. This phenomenon was consistent with the $\mathrm{pH}$-dependence of zeta potential as observed in our previous work [22], and could be attributed to the increased electrostatic attractions between the negatively charged $\mathrm{Au}(\mathrm{III})$ anions and the positively charged adsorption sites of chitosan at lower $\mathrm{pH}$ values although mixed gold chloride-hydroxide complexes might be present [16]. Because the isoelectric point of chitosan-coated magnetic nano-adsorbent was 5.95, the low adsorption capacity in alkaline solutions might be referred to the fact that chitosan-coated magnetic nano-adsorbent was not positively charged. Since the maximum adsorption capacity occurred at $\mathrm{pH} 2$ in the examined $\mathrm{pH}$ range, the following adsorption studies were carried out at $\mathrm{pH} 2$.

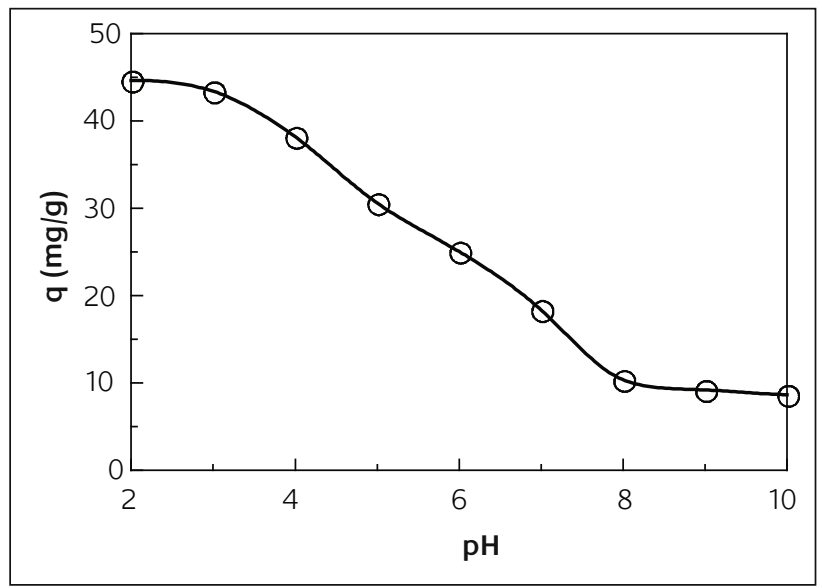

Figure 1

Effect of $\mathrm{pH}$ on the adsorption of Au(III) ions by the chitosan-coated magnetic nano-adsorbent at $25^{\circ} \mathrm{C}$ and an initial $\mathrm{Au}(\mathrm{III})$ ion concentration of $1039 \mathrm{mg} / \mathrm{l}$

\section{Adsorption isotherms}

The equilibrium isotherm for the adsorption of $\mathrm{Au}(\mathrm{III})$ ions by the chitosan-coated magnetic nano-adsorbent at $\mathrm{pH} 2$ and $25^{\circ} \mathrm{C}$ was shown in Fig. 2. The equilibrium data were fitted by Langmuir and Freundlich isotherm equations. The Langmuir equation can be expressed as:

$$
\frac{C_{e}}{q_{e}}=\frac{C_{e}}{q_{m}}+\frac{1}{q_{m} K_{L}}
$$

where $q_{\mathrm{e}}$ is the equilibrium $\mathrm{Au}(\mathrm{III})$ ion concentration on the adsorbent $(\mathrm{mg} / \mathrm{g}), C_{e}$ is the equilibrium $\mathrm{Au}(\mathrm{III})$ ion concentration in solution ( $\mathrm{mg} / \mathrm{l}), q_{\mathrm{m}}$ is the maximum capacity of adsorbent $(\mathrm{mg} / \mathrm{g})$, and $K_{\mathrm{L}}$ is the Langmuir adsorption constant $(1 / \mathrm{mg})$. The linear form of Freundlich equation, which is an empirical equation used to describe heterogeneous adsorption systems, can be represented as follows:

$$
\ln q_{e}=\ln K_{F}+\frac{1}{n} \ln C_{e}
$$

where $q_{\mathrm{e}}$ is the equilibrium $\mathrm{Au}(\mathrm{III})$ ion concentration on the adsorbent $(\mathrm{mg} / \mathrm{g}), C_{e}$ is the equilibrium $\mathrm{Au}(\mathrm{III})$ ion concentration in solution $(\mathrm{mg} / \mathrm{l}), K_{\mathrm{F}}$ is Freundlich constant $(1 / \mathrm{mg})$, and $n$ is the heterogeneity factor. The equilibrium isotherm for the adsorption of $\mathrm{Au}(\mathrm{III})$ ions was shown in Fig. 2 and the corresponding Langmuir and Freundlich constants and correlation coefficients $(R)$ were listed in Table 1. From the comparison of correlation coefficients, it was found that the data were fitted better by Langmuir equation than by Freundlich equation, revealing the adsorption of $\mathrm{Au}(\mathrm{III})$ ions on the chitosan-coated magnetic nano-adsorbent obeyed the Langmuir adsorption isotherm. From the slope and intercept in the inset of Fig. 2 , the values of $q_{\mathrm{m}}$ and $K$ might 
Table 2

Kinetic parameters for the adsorption of Au(III) ions by the chitosan-coated magnetic nano-adsorbent at various initial Au(III) ion concentrations and temperatures

\begin{tabular}{|c|c|c|c|c|c|c|c|c|c|}
\hline $\begin{array}{l}C_{0} \\
(\mathrm{mg} / \mathrm{l})\end{array}$ & $\begin{array}{c}\mathrm{T} \\
\left({ }^{\circ} \mathrm{C}\right)\end{array}$ & $\begin{array}{l}k_{1} \times 10^{3} \\
\left(\mathrm{~min}^{-1}\right)\end{array}$ & $R_{1}^{2}$ & $\begin{array}{c}k_{2} \times 10^{3} \\
(\mathrm{~g} / \mathrm{mg} / \mathrm{min})\end{array}$ & $\begin{array}{c}\mathrm{q}_{2} \\
(\mathrm{mg} / \mathrm{g})\end{array}$ & $R_{2}{ }^{2}$ & $\begin{array}{c}k_{\mathrm{p}} \\
\left(\mathrm{mg} / \mathrm{g} / \mathrm{min}^{1 / 2}\right)\end{array}$ & $\begin{array}{c}\mathrm{C} \\
(\mathrm{mg} / \mathrm{g})\end{array}$ & $R_{\mathrm{p}}{ }^{2}$ \\
\hline 644 & 25 & 5.68 & 0.935 & 28.83 & 31.04 & 1.000 & 0.31 & 26.57 & 0.618 \\
\hline 1039 & 25 & 7.58 & 0.938 & 8.09 & 44.76 & 0.999 & 0.71 & 34.35 & 0.885 \\
\hline 1283 & 25 & 2.81 & 0.903 & 5.93 & 48.73 & 0.999 & 0.61 & 38.26 & 0.936 \\
\hline 1539 & 25 & 4.30 & 0.963 & 1.05 & 52.74 & 0.983 & 1.27 & 28.38 & 0.954 \\
\hline 1039 & 15 & 5.30 & 0.893 & 6.57 & 46.21 & 0.999 & 0.49 & 37.48 & 0.931 \\
\hline 1039 & 35 & 4.54 & 0.887 & 8.91 & 46.06 & 1.000 & 0.49 & 38.16 & 0.841 \\
\hline
\end{tabular}

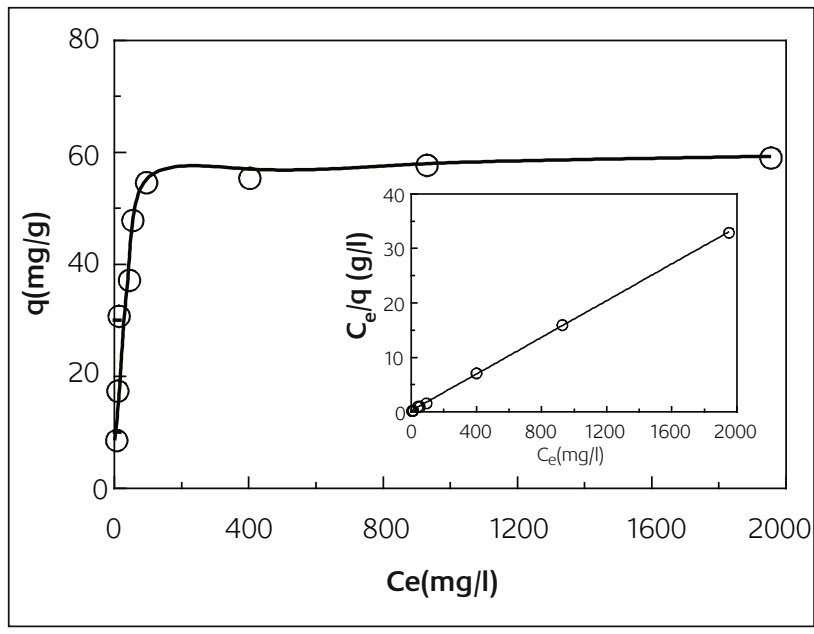

\section{Figure 2}

Equilibrium isotherm for the adsorption of $A$ (III) ions on the chitosancoated magnetic nano-adsorbent at $\mathrm{pH} 2$ and $25^{\circ} \mathrm{C}$. The inset illustrates the linear dependence of $\mathrm{C}_{e} / q$ on $\mathrm{C}_{\mathrm{e}}$

be estimated as $59.52 \mathrm{mg} / \mathrm{g}$ and $0.066 \mathrm{l} / \mathrm{mg}$, respectively. Based on the weight of coated chitosan, the maximum adsorption capacity could be calculated to be $1210 \mathrm{mg} / \mathrm{g}$. This was significantly higher than the values 33.9 and 591 $\mathrm{mg} / \mathrm{g}$ observed for the adsorption of $\mathrm{Au}$ (III) ions on microbeads of chitosan derivatives by Ngah et al. [25] and Arrascue et al. [16], respectively. This might be reasonably referred to the high specific surface area because the coated chitosan might be spread on the surface of $\mathrm{Fe}_{3} \mathrm{O}_{4}$ cores, leading to that almost all amino groups were available.

In addition, it was noteworthy that the equilibrium $\mathrm{Au}$ (III) ion concentration was almost undetectable $(<1 \mathrm{mg} / \mathrm{l})$ when the initial Au(III) ion concentration was less than $100 \mathrm{mg} / \mathrm{l}$. This revealed the chitosan-coated magnetic nano-adsorbent was quite efficient for the adsorption of $\mathrm{Au}(\mathrm{III})$ ions and could reduce the $\mathrm{Au}(\mathrm{III})$ ions to a concentration level less than $1 \mathrm{mg} / \mathrm{l}$.

\section{Adsorption kinetics}

The kinetics for the adsorption of $\mathrm{Au}(\mathrm{III})$ ions on the chitosancoated magnetic nano-adsorbent at $\mathrm{pH} 2$ was investigated. The effect of initial $\mathrm{Au}(\mathrm{III})$ ion concentration was shown in Fig. 3(a). It was obvious that about $90 \%$ of the equilibrium adsorption capacity could be achieved after 30 min and the adsorption equilibrium was completely achieved after 6-12 h, increasing with the increase of initial $\mathrm{Au}(\mathrm{III})$ ion concentration. Since the chitosan with smaller particle size had a higher
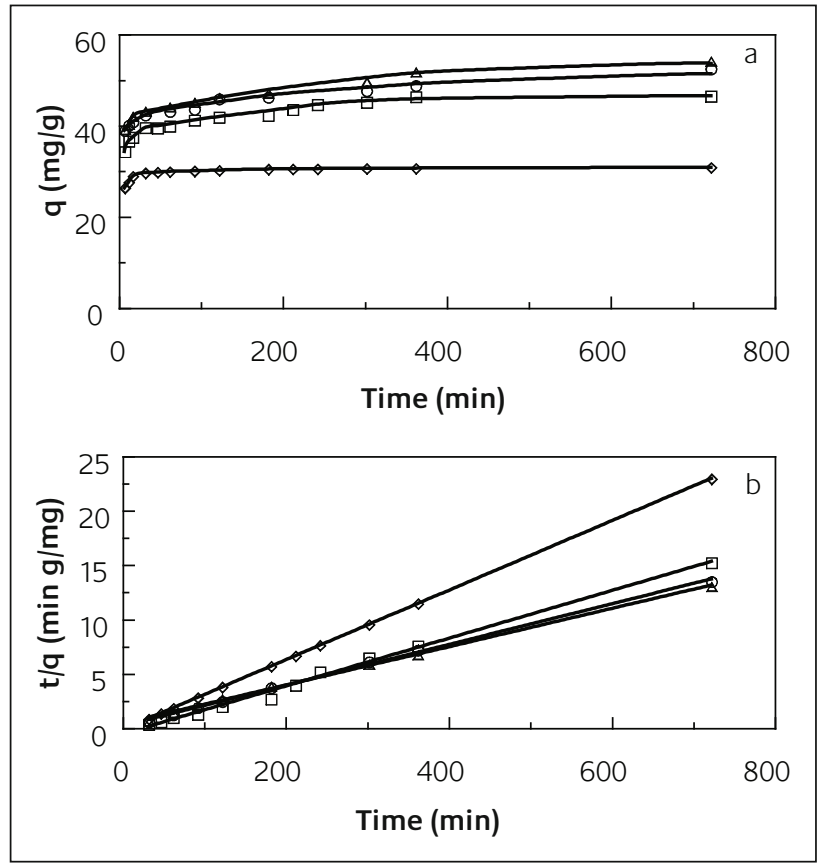

Figure 3

(a) Effect of initial Au(III) ion concentration on the adsorption kinetics of $\mathrm{Au}(\mathrm{III})$ ions by the chitosan-coated magnetic nano-adsorbent at $\mathrm{pH} 2$ and $25^{\circ} \mathrm{C}: 644$ ( 6 ), 1039 (), 1283 (O), and 1539 (口) $\mathrm{mg} / \mathrm{l}$. (b) The linear dependence of $t / q$ on $t$

adsorption rate due to the availability of larger specific surface area on the adsorbent [12], the contact time required to reach the equilibrium was shorter for the magnetic nanoadsorbent in this study than those for the micro-sized adsorbents reported in the literatures $[5,16,25]$.

Three kinetic models were tested to find out the appropriate adsorption rate expression: the pseudo-firstorder equation [26], pseudo-second-order equation [27], and intraparticle diffusion model [28] as expressed below

$$
\begin{aligned}
& \ln \frac{\left(q_{e}-q_{t}\right)}{q_{e}}=-k_{1} t \\
& \frac{t}{q_{t}}=\frac{1}{k_{2} q_{2}^{2}}+\frac{1}{q_{2}} t \\
& q_{t}=k_{p} t^{1 / 2}+C
\end{aligned}
$$

where $q_{t}$ is the amount of dye adsorbed $(\mathrm{mg} / \mathrm{g})$ at time $t, q_{e}$ is the maximum adsorption capacity $(\mathrm{mg} / \mathrm{g})$ for pseudo-firstorder adsorption, $k_{1}$ is the pseudo-first-order rate constant 
Table 3

Thermodynamic parameters for the adsorption of Au(III) ions by the chitosan-coated magnetic nano-adsorbent at various temperatures calculated from the second-order rate constants

\begin{tabular}{|c|c|c|c|c|c|}
\hline $\mathrm{T}\left({ }^{\circ} \mathrm{C}\right)$ & $E_{a}(\mathrm{~kJ} / \mathrm{mol})$ & $K^{*}(\mathrm{~g} / \mathrm{mg}) \times 10^{-17}$ & $\Delta G^{*}(\mathrm{~kJ} / \mathrm{mol})$ & $\Delta H^{*}(\mathrm{~kJ} / \mathrm{mol})$ & $\Delta S^{*}(\mathrm{~J} / \mathrm{mol})$ \\
\hline 15 & & 18.25 & 86.77 & 8.88 & -270.4 \\
\hline 25 & 11.28 & 21.72 & 89.36 & 8.80 & -270.3 \\
\hline 35 & & 23.14 & 119.13 & 8.72 & -358.5 \\
\hline
\end{tabular}

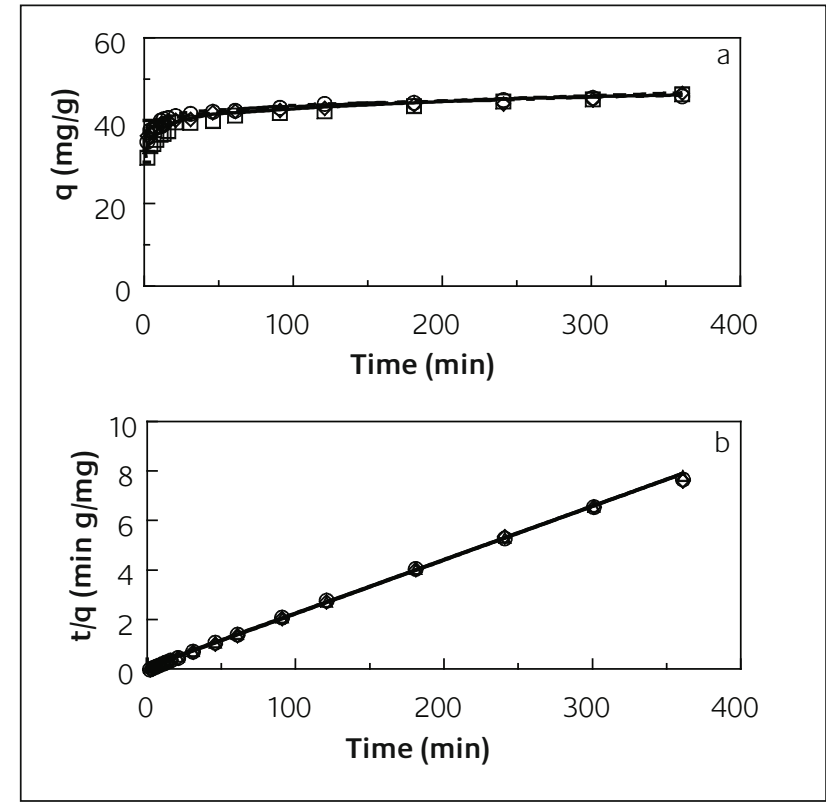

\section{Figure 4}

(a) Effect of temperature on the adsorption kinetics of Au(III) ions by the chitosan-coated magnetic nano-adsorbent at $\mathrm{pH} 2$ and an initial

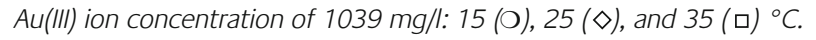
(b) The linear dependence of $t / q$ on $t$

(min), $q_{2}$ is the maximum adsorption capacity (mg/g) for pseudo-second-order adsorption, $k_{2}$ is the pseudo-secondorder rate constant ( $\mathrm{g} / \mathrm{mg} / \mathrm{min}), C$ is the intercept, and $k_{p}$ is the intraparticle diffusion rate constant $\left(\mathrm{mg} / \mathrm{g} / \mathrm{min}^{1 / 2}\right)$.

The kinetic parameters $\left(k_{1}, k_{2}, k_{p}, q_{1}, q_{2}, C\right)$ and correlation coefficients $\left(R_{1}^{2}, R_{2}^{2}, R_{p}^{2}\right)$ of $\mathrm{Au}(\mathrm{III})$ ions were calculated and listed in Table 2. The correlation coefficients revealed the adsorption data were best fitted by the pseudo-second-order kinetic model, revealing the rate limiting step may be chemical sorption involving valency forces through sharing or exchange of electrons between chitosan and Au(III) ions [27]. As shown in Fig. $3(\mathrm{~b})$, all the plots of $t / q_{t}$ vs $t$ at various initial concentrations yield straight lines. In addition, it was notable that the correlation coefficients for intraparticle diffusion model were much below 1, indicating the adsorption process significantly deviated from the intraparticle diffusion kinetic model. This is reasonable because the adsorption of $\mathrm{Au}(\mathrm{III})$ ions occurred only on the surface of chitosan-coated $\mathrm{Fe}_{3} \mathrm{O}_{4}$ nanoparticles and the intraparticle diffusion resistance was absent.

\section{Thermodynamic parameters}

The effect of temperature on the adsorption of $\mathrm{Au}(\mathrm{III})$ ions by the chitosan-coated magnetic nano-adsorbent was not obvious as shown in Fig. 4(a). By fitting the adsorption data with the above three kinetic models, it revealed that the pseudo-second-order kinetic model was still the best one for the adsorption of $\mathrm{Au}(\mathrm{III})$ ions at different temperatures. The kinetic parameters $\left(k_{1}, k_{2}, k_{p}, q_{1}, q_{2}, C\right)$ and correlation coefficients $\left(R_{1}^{2}, R_{2}^{2}, R_{p}^{2}\right)$ were given in Table 2 , and the plots of $t / q_{t}$ vs $t$ at different temperatures also yield straight lines as shown in Fig. 4(b).

In spite of the weak temperature-dependence, from the rate constants $\left(k_{2}\right)$ at different temperatures, the thermodynamic parameters for the adsorption process could be evaluated. The activation energy $\left(E_{a}\right)$ was obtained from the Arrhenius plot. The other activation parameters such as activation free energy change $\left(\Delta G^{*}\right)$, activation enthalpy change $\left(\Delta H^{*}\right)$, and activation entropy change $\left(\Delta S^{*}\right)$, were calculated by the following equations [29-30]

$$
\begin{gathered}
\ln k_{2}=\ln A-\frac{E_{a}}{R T} \\
k_{2}=\frac{k_{B} T}{h} K^{*} \\
\Delta G^{*}=-R T \ln K^{*} \\
\Delta H^{*}=-E_{a}-R T \\
\Delta S^{*}=\frac{\Delta H^{*}-\Delta G^{*}}{T}
\end{gathered}
$$

where $E_{a}$ is the Arrenius activation energy, $A$ is the Arrenius factor, $k_{B}$ and $h$ are Boltzmann's and Planck's constants, respectively, $R$ is the gas constant, and $K^{*}$ is the equilibrium constant at temperature $T$. From the slope of the linear plot of In $k_{2}$ vs $1 / T$ (shown in Fig. 5), the activation energy was obtained as $11.28 \mathrm{~kJ} \mathrm{~mol}^{-1}$. Usually the activation energy of

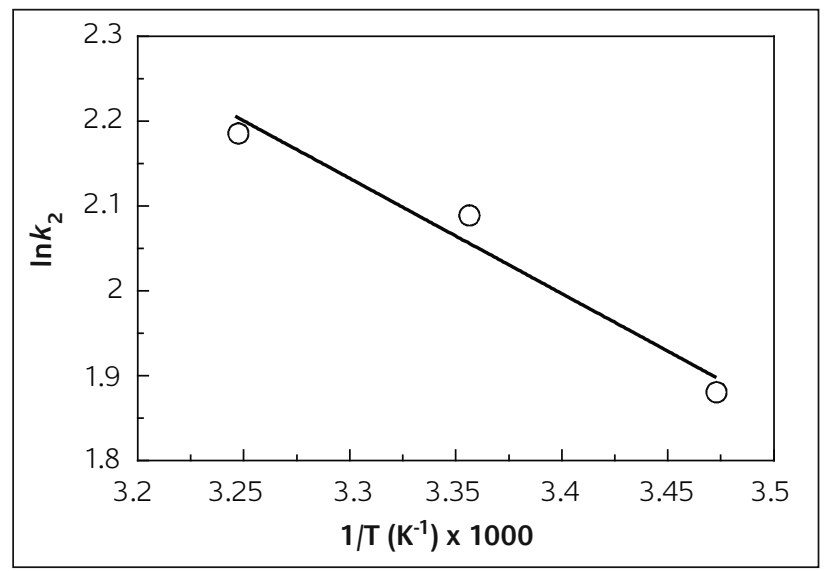

Figure 5

Effect of temperature on the rate constant for the adsorption of Au(III) ions by the chitosan-coated magnetic nano-adsorbent at $\mathrm{pH} 2$ and an initial Au(III) ion concentration of 1039 mg/l 
physical adsorption is $5-40 \mathrm{~kJ} / \mathrm{mol}$ while that of chemical adsorption is (40-800 kJ/mol) [31], so the adsorption of $\mathrm{Au}(\mathrm{III})$ ions on the chitosan-coated magnetic nano-adsorbent should be physical adsorption. This was reasonable because $\mathrm{Au}(\mathrm{III})$ ions were adsorbed on the chitosan via the ion-ion interaction.

The activation energy and other thermodynamic parameters were listed in Table 3 . The positive values of $E_{a}, \Delta G^{*}, \Delta H^{*}$ indicate the presence of an energy barrier in the adsorption process. This is quite common and reasonable because the activated complex in the transition state is an excited form. Furthermore, the negative value of $\Delta S^{*}$ was resulted from the decreased randomness due to the adsorption of $\mathrm{Au}(\mathrm{III})$ ions.

\section{Conclusion}

The adsorption of $\mathrm{Au}(\mathrm{III})$ ions by the chitosan-coated $\mathrm{Fe}_{3} \mathrm{O}_{4}$ nanoparticles via the anion exchange in aqueous solutions was studied. The adsorption capacity increased with the decrease in $\mathrm{pH}$ owing to the protonation of the amino groups of chitosan. The equilibrium isotherm could be described by the Langmuir equation, and the adsorption process obeyed the pseudo-second-order kinetic model with a shorter time required for reaching the equilibrium than those using the micro-sized adsorbents. Such a magnetic nano-adsorbent is useful for the efficient removal of $\mathrm{Au}(\mathrm{III})$ ions or other valuable metal anions from the aqueous solutions.

The authors thank the National Science Council of the Republic of China for support (NSC 93-2214-E006-023).

\section{About the authors}

Dr. Yang-Chuang Chang received his $\mathrm{PhD}$ in Chemical Engineering at National Cheng Kung University (Taiwan), focusing on the fabrication and applications of multifunctional magnetic nano-carriers. He currently is a researcher at Institute of Nuclear Energy Research (Taiwan), working on the development of fuel cells.

Dr. Dong-Hwang Chen is a professor of Chemical Engineering Department at National Cheng Kung University (Taiwan). His research works include the synthesis of nanoparticles, the fabrication of functional composite nanoparticles and thin films, the applications of surfacemodified magnetic nanoparticles in separation, catalysis, and biomedicine, as well as the development of composite nanomaterials for electromagnetic wave absorption.

\section{References}

1

2

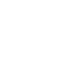

\section{3, 71, 191}

17 M. Ruiz, A.M. Sastre, E. Guibal, React. Funct. Polym., 2000, 45, 155

18 T.Y. Hsien, G.L. Rorrer, Sep. Sci. Technol., 1995, 30, 2455

19 T.Y. Hsien, G.L. Rorrer, Ind. Eng. Chem. Res., 1997, 36, 3631

20 A.L. Debbaudt, M.L. Ferreira, M.E. Gschaider, Carbohydr. Polym., 2004, 56, 321

21 M.W. Wan, I.G. Petrisor, H.T. Lai, D. Kim, T.F. Yen, Carbohydr. Polym., 2004, 55, 249

22 Y.C. Chang, D.H. Chen, J. Colloid Interface Sci., 2005, 283, 446

23 Y.C. Chang, D.H. Chen, Macromol. Biosci., 2005, 5, 254

24 Y.C. Chang, D.B. Shieh, C.H. Chang, D.H. Chen, J. Biomed. Nanotechnol., 2005, 1, 196

29 R.S. Juang, F.C. Wu, R.L. Tseng, Environ. Technol., 1997, 18, 525

30 W. Stumm, J.J. Morgan, Aquatic Chemistry: An Introduction Emphasizing Chemical Equilibria in Natural Waters, 2nd edn, J. Wiley \& Sons, New York, 1981

31 H. Nollet, M. Roels, P. Lutgen, P. Van der Meeren, W. Verstrate, Chemosphere, 2003, 53, 655 